Braz. J. Aquat. Sci. Technol., 2010, 14(1): 51-63.

\title{
PERIGOS E RISCOS ASSOCIADOS A PROCESSOS COSTEIROS NO LITORAL SUL DO BRASIL (RS): UMA SINTESE.
}

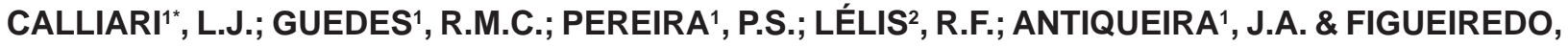 \\ S.A. \\ 1. Universidade Federal do Rio Grande (FURG), Av. Itália km 8, Campus Carreiros, Cep: 96201-900. \\ Rio Grande-RS. \\ 2. Softplan Polygraph, Florianópolis-SC. \\ *Corresponding author: Icalliari@log.furg.br
}

\begin{abstract}
Calliari, L.J.; Guedes, R.M.C.; Pereira, P.S.; Lélis, R.F.; Antiqueira, J.A. \& Figueiredo, S.A. 2010. Hazards and risks associated to coastal processes along the southern Brazilian coastline: A synthesis. Braz. J. Aquat. Sci. Technol. 14(1): 51-63. ISSN 1808-7035. Some processes related to hydrodynamics, geomorphology and sediment movement represent coastal hazards and risks along the littoral of Rio Grande do Sul (RS) state in southern Brazil. The hazards imply in coastal erosion, habitat loss and environmental change. The risks are related to serious accidents including fatalities to the coastal users. Shoreface morphology, storms and washouts induce erosion at specific locations of the coastline. Storms and washouts, together with beach morphodynamics and depositional processes both aeolian and hydrodynamic embody latent risks to the physical integrity of people that live in and use this environment. Wave refraction patterns from SE to SW cause erosion in two coastal sectors at the proximities of Conceição Lighthouse and Hermenegildo Beach respectively located at the central and southernmost portion of the RS coastline. In both areas, the high number of washouts amplifies the erosion destroying foredunes and the subaerial beach. In addition, the lowlands of the barrier adjacent to small pocket lagoons in the northern littoral are more susceptible to washout erosion. Both, the refraction patterns and the washouts can be associated with two storms tracks and extra-tropical cyclones which magnify erosion and inundation of the coastal zone. The combination of higher population during summer seasons and intermediate beaches with considerable amounts of medium sand make beaches from the northern littoral and extreme south more risky for bathers. Coastline orientation in relation to the predominant NE wind causes wind-blow sand to invade the coastal plain in the form of transgressive dunes causing several hazards mainly in the northern littoral between Tramandaí and Mostardas. Short-term effects associated with episodic events of mud deposition during heavy storms on Cassino Beach influence the morphodynamics behavior on the sectors affected by the mud deposits creating coastal risks relating to beach usage.
\end{abstract}

Keywords: storm surges, beach morphodynamics, erosion, washouts, wind blow sand.

\section{INTRODUÇÃO}

Apesar de aparentar homogeneidade, a zona costeira do Rio Grande do Sul (RS) apresenta acentuadas diferenciações relacionadas à geomorfologia, orientação da linha de costa e textura sedimentar (Calliari et al. 2005). Tais fatores, associados à ocupação antrópica e a uma hidrodinâmica complexa e variável, resultante da alternância de condições de tempo ameno com a freqüente passagem de tempestades tanto moderadas e significativas como severas e extremas, cuja freqüência de ocorrência atinge respectivamente $42 \%$ e 3,5\% (Barletta \& Calliari, 2001; 2003), potencializam perigos costeiros naturais.

O objetivo do presente trabalho é descrever os perigos naturais e riscos da costa do RS o qual pode ser subdividido em litoral norte, central e sul abrangendo respectivamente os trechos entre Tôrres a Quintão, deste último a São José do Norte e daí ao Chuí, identificando os processos operantes (Figura 1). São apresentados dados compilados e também inéditos resultantes de diversos trabalhos de morfodinâmica e sedimentologia costeira desenvolvidos ao longo do lito- ral do RS pelo Laboratório de Oceanografia Geológica da Universidade Federal do Rio Grande (FURG).

\section{METODOLOGIA}

Os métodos de análise geomorfológica e diagramas de refração foram usados para identificar perigo de erosão na área do farol da Conceição e Hermenegildo. O primeiro leva em consideração a identificação de evidências morfológicas, litológicas e estruturais para identificar a erosão. O segundo considera a diferenciação do campo de ondas como uma razão dinâmica para a mesma. Assim, 15 anos de monitoramento de campo ao longo da costa do RS observando "sinais de erosão" tais como: presença de escarpas permanentes e sua composição litológica, afloramentos de depósitos lagunares e turfáceos no pós-praia, concentração de minerais pesados e largura da praia tem sido usados como indicadores de áreas de perigo de erosão. 
Calliari et al.: Riscos naturais na costa do RS.

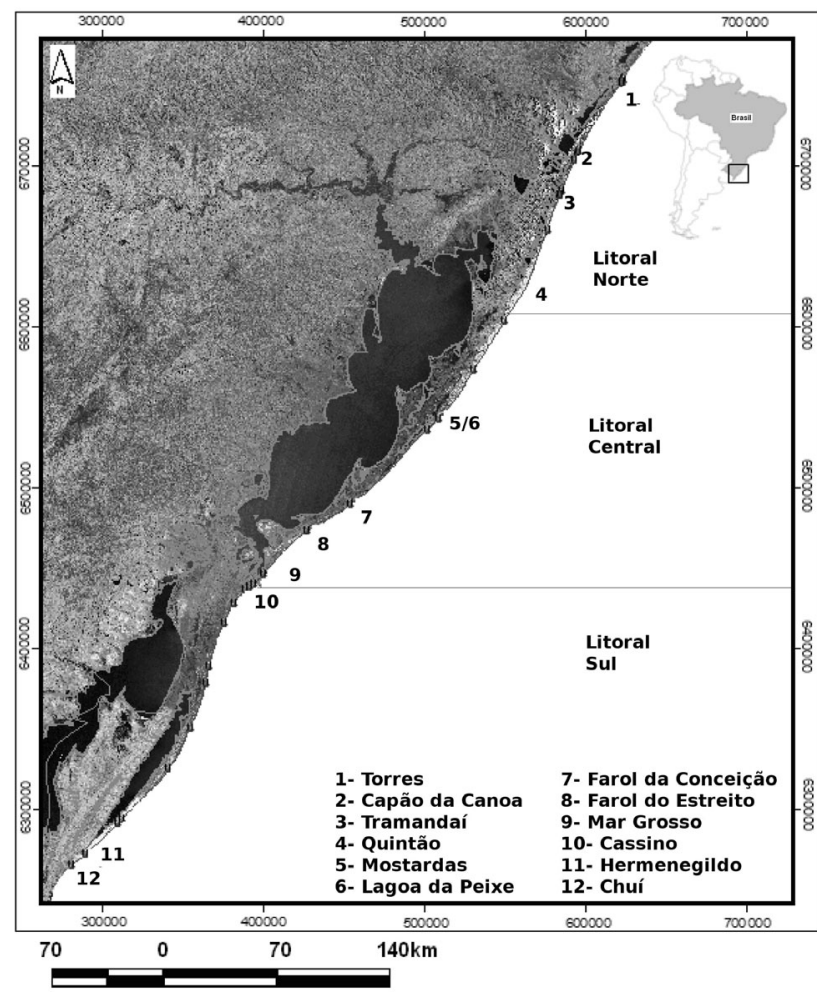

Figura.1. Mapa do litoral do Rio Grande do Sul.

Para o estudo do "efeito de foco" foram confeccionados diagramas de refração cobrindo o setor de varredura entre $50^{\circ}(\mathrm{NE})$ e $240^{\circ}(\mathrm{SW})$ para ondas com períodos compreendidos entre 5 e $18 \mathrm{~s}$, usando-se incrementos respectivamente de $10^{\circ}$ e $1 \mathrm{~s}$ (Speranski \& Calliari, 2006). Dentro desses limites foram analisadas a presença e estabilidade do "foco". O perigo de erosão em locais preferenciais de concentração de energia de ondas é magnificado quando determinados padrões de tempestade produzem marés meteorológicas na costa sul e sudeste do Brasil (Marone \& Camargo, 1994; Calliari et al., 1998; Tozzi, 1999; Saraiva et al., 2003; Parise, 2007).

Para a análise das marés meteorológicas, cartas barométricas e imagens de satélites meteorológicos, correlacionados com dados de direção e intensidade de vento, de perfis praiais e observações do nível d'água foram usadas na caracterização do fenômeno. Este mesmo enfoque foi incrementado pelo detalhamento dos padrões atmosféricos através da análise dos componentes zonais e meridionais do vento com resolução temporal mais detalhada. A reconstituição da formação, propagação, e dissipação dos ciclones extratropicais através de dados de Reanálise do NCEP/ NCAR (National Center for Environmental Prediction) associados à análise da vorticidade relativa na trajetória dos ciclones (Parise, 2007) tem propiciado um meIhor entendimento deste fenômeno.
A localização e número de sangradouros tanto efêmeros como permanentes associados a sistemas frontais os quais causam severa erosão no sistema de dunas frontais e na porção emersa da praia têm sido mapeados desde 1991 por vários programas de monitoramento mensal de praias entre Torres e Chuí. Os mesmos tem sido correlacionados com as condições meteorológicas sazonais (precipitação pluviométrica, direção e intensidade do vento) e com as características geomorfológicas da barreira arenosa (Pereira da Silva et al., 2003; Figueiredo \& Calliari, 2004)

Duas décadas de monitoramento de perfis de praia com dados hidrodinâmicos eventuais fornecidos por ondógrafos direcionais permitiram documentar vários episódios de deposição de lama na praia do Cassino associados a eventos de tempestade, capazes de remobilizar bolsões de lama transitórios localizados na ante-praia e zona de surf ao longo de um setor de $9 \mathrm{~km}$ de comprimento (Calliari et al., 2001; Calliari \& Griep, 1999). Diversas situações de risco foram identificadas durante e após esses eventos deposicionais.

O monitoramento de praias tem sido realizado desde 1990 a fim de caracterizar os estágios praiais ao longo da costa do RS. Foram realizadas campanhas de levantamento topográfico, levantamento aéreo digital utilizando o sistema ADAR-1000 e coleta de sedimento nos $30 \mathrm{~cm}$ superficiais do estirâncio.

As praias enfocadas nestes estudos estão localizadas no litoral norte e sul do estado, excluindo-se aqui o setor denominado de litoral central, região pouco habitada e freqüentada por banhistas. São elas: Praia Grande (Torres), Capão da Canoa, Tramandaí, Cassino, Hermenegildo e Barra do Chuí, respectivamente enumeradas do norte para o sul na Figura 1. Para os perfis realizados foram calculados os parâmetros morfométricos: índice de mobilidade (óyb) e o coeficiente de variação da largura média da praia (CV), os quais constituem excelentes indicadores da mobilidade associada a cada estágio (Short \& Hesp, 1982).

Desde 2005, a morfodinâmica da zona de arrebentação da Praia do Cassino vem sendo estudada através de um sistema de sensoriamento remoto baseado em vídeo (Sistema Argus), instalado no balneário Querência, localizado 8 km ao sul dos molhes da Barra. O sistema captura e armazena imagens durante intervalos e em freqüências de amostragem determinados. A média no tempo de imagens armazenadas durante os intervalos de aquisição permitem a obtenção de imagens de longa exposição, cuja posição de quebra das ondas, indicada através da presença de espuma branca, torna-se bem definida em função da quebra preferencial sobre os bancos, a qual resulta na concentração de espuma sobre suas posições (Lippmann \& Holman, 1989). Desta forma, estas imagens fornecem excelentes estimativas com relação à morfologia 
plana e posição dos bancos arenosos na zona de arrebentação. A análise destas imagens de forma conjunta a perfis de praia obtidos em alta freqüência no local tem permitido a identificação de padrões tridimensionais dos bancos no local (Guedes, 2006; 2008), a despeito de suas características dissipativas e de granulometria fina.

O mapeamento da altura das dunas frontais ao longo da costa do RS enfocando a orientação da mesma em relação ao vento predominante (Calliari et al., 2005), associado às características geomorfológicas dos sistemas eólicos sobre a barreira holocênica, permite identificar locais sob intenso solapamento por processos eólicos, cujos impactos na costa do RS são crônicos e relacionados principalmente a invasão de balneários, rodovias e ambientes naturais. Entretanto, em alguns casos os problemas se acentuam, pondo em risco vidas humanas e perda de propriedade.

\section{RESULTADOS E DISCUSSÃO}

\section{Perigos de erosão associados à morfologia da ante-praia.}

O processo de transformação das ondas em águas rasas relacionado à refração sobre batimetria irregular é atribuído como uma das causas principais da erosão localizada para os setores costeiros do Farol da Conceição e praia do Hermenegildo, localizados respectivamente no litoral central e sul do RS. TrabaIhos prévios (Speranski \& Calliari, 2001) mostraram a existência no setor central de dois focos estáveis atuantes sobre estas áreas (Figura 2).

Padrões convergentes foram identificados para ondas relativamente longas (períodos maiores que $9 \mathrm{~s}$ ) provenientes de SSE-SW. A associação entre observações morfológicas atuais e diagramas de refração mostra que a erosão localizada da ordem de $30 \mathrm{Km}$ está associada ao padrão de refração das ondas de tempestade que se propagam sobre locais de batimetria complexa. Na porção sul o setor erosivo abrange a região compreendida entre um ponto localizado cerca de $15 \mathrm{Km}$ ao norte da praia do Hermenegildo e Chuí (Figura 1). O setor do Hermenegildo ao Chuí apresenta um grande intervalo de ocorrência de focos entre 80 e $135^{\circ}$ para períodos de 12 a $15 \mathrm{~s}$ (Pimenta, 1999). Segundo este autor, a partir do ângulo de incidência de ondas de $135^{\circ}$ o Foco $2 \mathrm{~B}$ (Figura 3 ) ganha grande intensidade sobre a região do Hermenegildo - Chuí, onde fixa sua posição e se mantém estável entre os ângulos de 110 e $140^{\circ}$. Nesta região o processo de formação dos focos demonstrou ser governado não só por influência dos bancos presentes na plataforma interna, mas também pela ação conjunta de depressões batimétricas, que
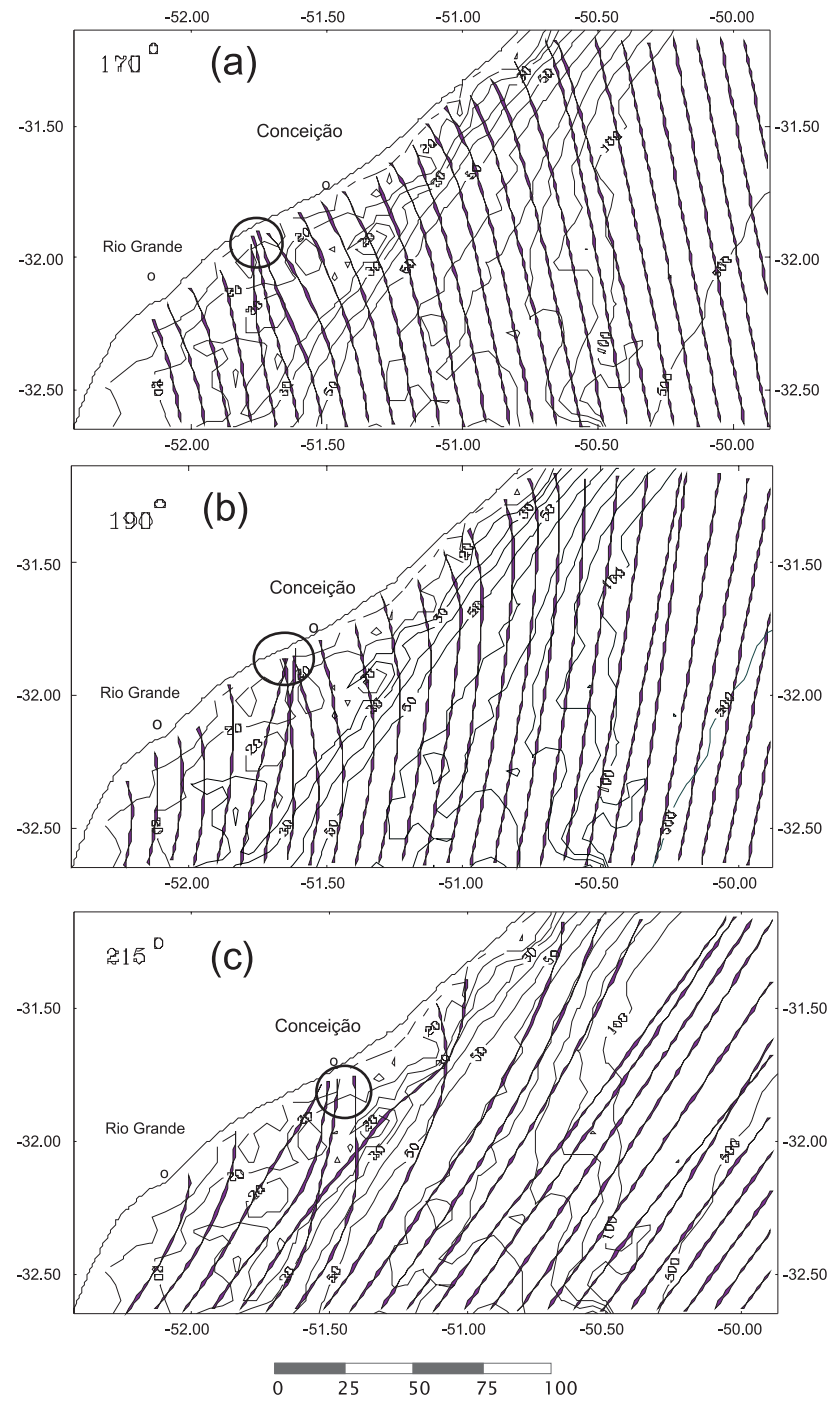

Figura 2. Diagramas de refração na costa do RS para ondas provenientes das direções $170^{\circ}$ (a), $190^{\circ}$ (b) e $215^{\circ}$ (c). Modificado de Pimenta (1999).

quando justapostas podem atuar como uma única lente convergente.

Sob o enfoque da geomorfologia costeira, sabese que a ocorrência de focos estáveis reflete no aumento de altura das ondas na costa. Esses gradientes laterais de altura de ondas apresentam potencial para gerar correntes paralelas à praia, as quais transportam sedimentos e contribuem para um balanço negativo de sedimentos nessas regiões. A estabilidade de foco sugere que o processo de concentração de energia juntamente com a incidência oblíqua das ondas provindas do quadrante sul durante tempestades (Speranski \& Calliari, 2001) seja a causa principal da erosão costeira nestes locais.

Taxas de recuo da linha de costa monitorados nos últimos 15 anos para o Farol da Conceição e praia do Hermenegildo indicam respectivamente valores de 3,6 m/ano (Barletta \& Calliari, 2001) e 2,5 m/ano (Calliari 
Calliari et al.: Riscos naturais na costa do RS.
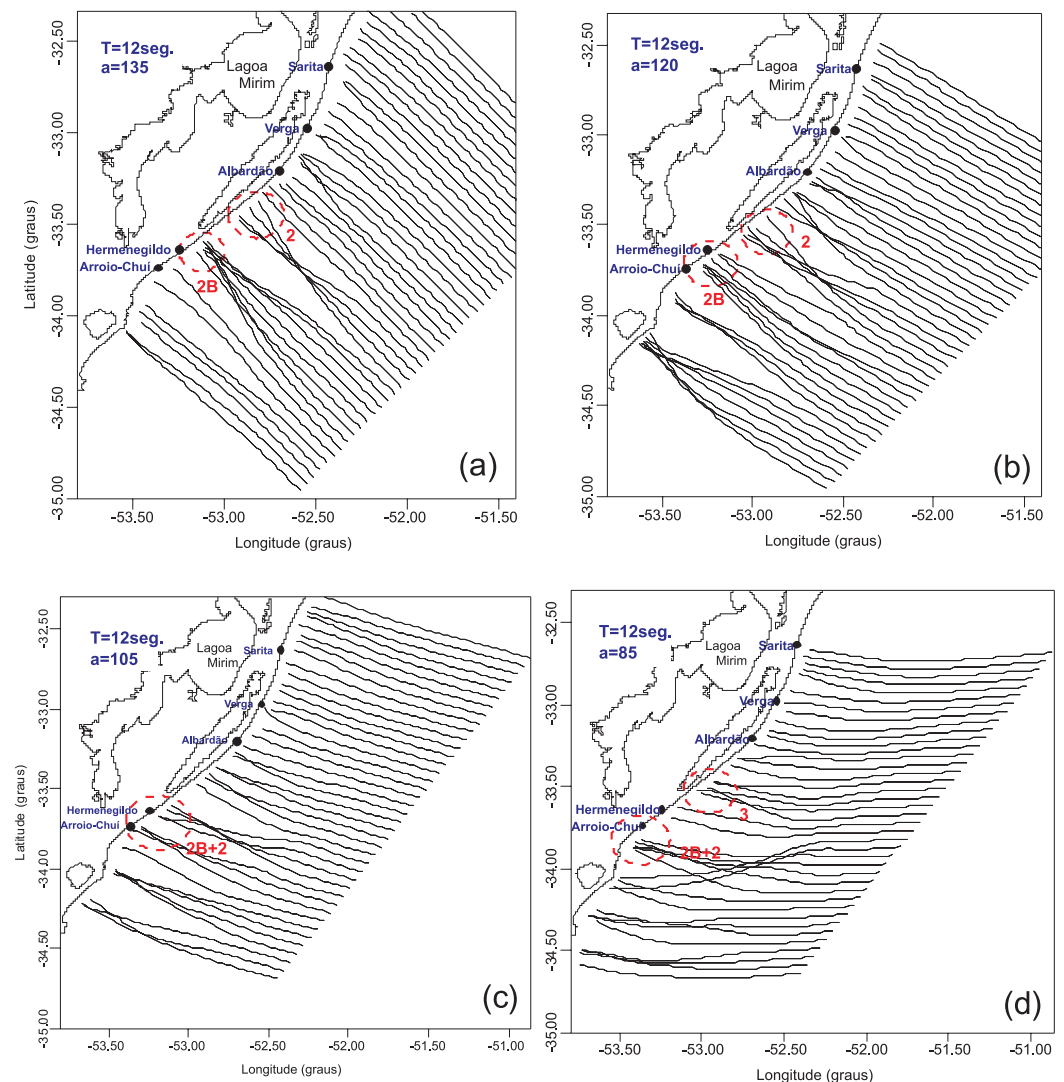

Figura 3. Diagramas de refração de ondas com período 12 segundos, provenientes de: $135^{\circ}$ (a), $120^{\circ}$ (b), $105^{\circ}$ (c) e $85^{\circ}$ (d). Modificado de Pimenta (1999).

et al. 1998). Estes são atualmente os principais locais de erosão natural permanente na costa do RS. No caso da praia do Hermenegildo o processo natural foi magnificado pela urbanização excessivamente próxima ou sobre as dunas frontais. Tais locais encaixamse no moderno conceito de "hot spot" erosivo (McNinch, 2004) ou Zona de Erosão Acentuada (ZEA) (Klein et al. 2009; Araújo et al. neste volume) ou seja, locais caracterizados por erosão acentuada devido à associação de processos hidrodinâmicos e características geológicas relacionadas à evolução geomorfológica costeira. No caso do setor do Farol da Conceição, mudanças abruptas com declividade acentuada no perfil da antepraia e a presença de afloramentos rochosos na zona de arrebentação (Buchmann \& Tomazelli, 2003) (Figura 4a) são fatores adicionais que propiciam escassez de sedimentos arenosos, e conseqüentemente dificuldade de recomposição do perfil praial após eventos de tempestade. As figuras $4 b$ e $4 c$ mostram a erosão acentuada que culminou com a queda do Farol em 1993 e a posterior destruição da casa do faroleiro em 1999.

\section{Perigos de erosão e inundação devido às marés meteorológicas e ondas de tempestade.}

Erosão costeira associada a inundações pela ação da água do mar em costas baixas é principalmente gerada pela ação de tempestades, as quais cau- sam sobre-elevação do nível do mar acima da maré normal. Essa elevação do nível da água é denominada na literatura mundial de "storm surge", definida basicamente como a diferença de nível entre a maré prevista (astronômica) e a maré observada, e vem sendo referida na literatura nacional como maré meteorológica.

$\mathrm{Na}$ costa sul do RS elevações da ordem de 1,5 m acima da maré prevista já foram observadas (Calliari et al., 1998; Saraiva et al., 2003), causando acentuada erosão costeira tanto em áreas urbanizadas como não ocupadas. A erosão é maximizada quando a sobre-elevação coincide com o pico da preamar de sizígia, resultando em elevações de nível amplificadas. Vários fatores contribuem para a ocorrência de marés meteorológicas: o empilhamento de água junto à zona costeira em função efeito do transporte de Ekmanagindo sobre os ventos fortes soprando sobre longas pistas oceânicas, paralelas à costa, e de direção SW para o caso da costa do RS (wind set-up); a baixa pressão barométrica geralmente associada ao centro de baixa pressão, que aumenta o nível do oceano; o aumento da altura da arrebentação, que resulta também no aumento do nível do mar na zona de surfe interna (wave setup) e fatores adicionais, tais como a duração do vento, presença ou não do ciclone associado e a velocidade de seu deslocamento, trajetória e distância da costa. 
(a)

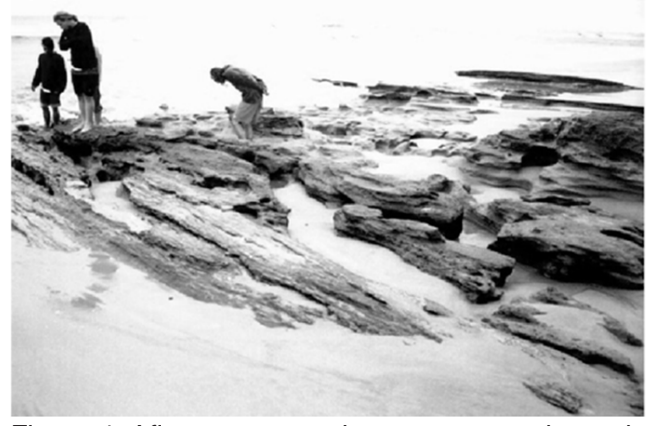

(b)

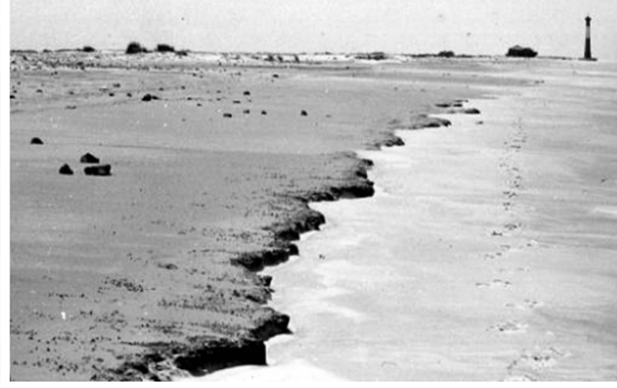

(c)

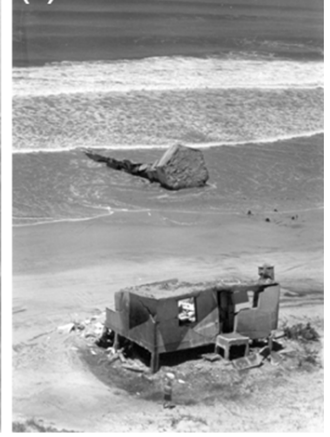

Figura 4. Afloramentos rochosos na zona de arrebentação do Farol Conceição (a). Afloramentos de turfa, farol e casa em 1993 antes da queda (b). Farol caído e destruição da casa do faroleiro em 1999 (c). Fotos: Francisco S. Buchmann, Lauro Calliari e Pedro Pereira, respectivamente.

Apesar da escala de atuação das marés meteorológicas atingir centenas de quilômetros, tem se tornado cada vez mais evidente a relação entre os setores que sofrem erosão severa e a trajetória das tempestades extratropicais. Calliari et al. (1998) descrevem um evento de erosão intensa na praia do Hermenegildo, o qual foi causado pelo deslocamento de um sistema atmosférico originado no sul da Argentina cujos centros de baixa e alta pressão mantiveramse respectivamente no oceano e no continente. Tozzi (1999), monitorando a ação de tempestades ao longo de sete pontos do litoral sul do RS identificou quatro classes de tempestades: as tempestades costeiras de Leste/Sudeste afastadas e de Sul/Sudeste próximas à costa, que determinam respectivamente baixas e moderadas alterações nas praias, e as tempestades sazonais do meio do Atlântico e ciclones Extratropicais, responsáveis por erosão severa.

Recentemente, Parise (2007), monitorando 23 tempestades extratropicais ocorridas entre junho de 2006 e julho de 2007 , encontrou três trajetórias de ci- clones: ciclogênese ao sul da Argentina afastada da costa com deslocamento para leste e trajetória entre $47,5^{\circ}$ S e $57,5^{\circ}$ S; ciclogênese próxima a costa ao sul do Uruguai com padrões de deslocamento para leste e trajetória entre $35^{\circ} S$ e $42,5^{\circ} S$; e ciclogênese próxima a costa ao sul do Uruguai com deslocamento para sudeste e trajetória entre $35^{\circ} \mathrm{S}$ e $57,5^{\circ} \mathrm{S}$. As duas últimas (Figuras 5a e 5b, respectivamente) produzem respectivamente maior erosão e maior inundação na praia do Cassino, e correspondem respectivamente às tempestades sazonais do meio do Atlântico e os ciclones extratropicais da classificação de Tozzi (1999).

\section{Perigos e riscos associados à ocorrência de "sangradouros"}

Sangradouros desempenham um papel importante na drenagem da descarga pluvial dos setores alagadiços do campo de dunas para a zona de arrebentação. O numero e distribuição especial destas feições varia ao longo da costa em função da sazonalidade, geologia e geomorfologia da planície cos-
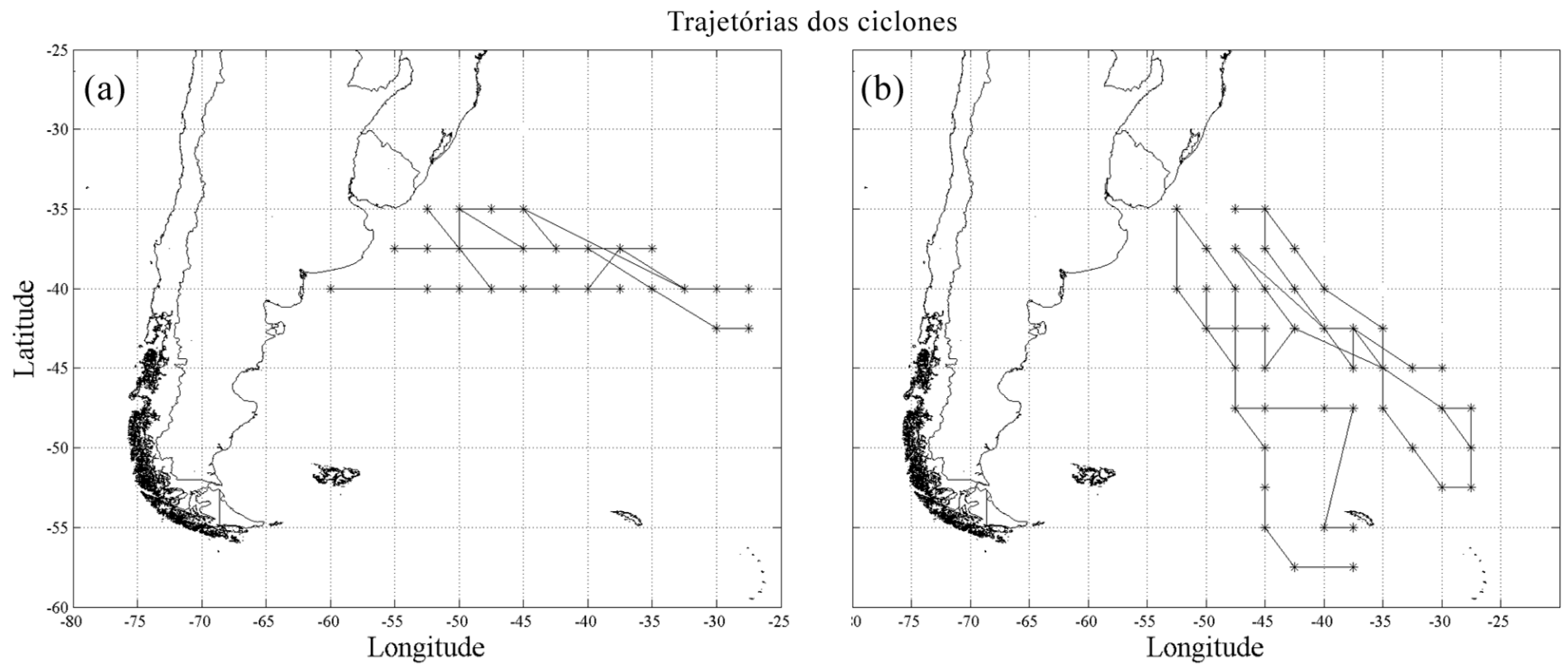

Figura 5. Ciclogêneses próximas à costa ao sul do Uruguai, com deslocamento para leste (a) e sudeste (b). Modificado de Parise (2007). 
Calliari et al.: Riscos naturais na costa do RS.

teira adjacente (Figueiredo e Calliari, 2004). Geralmente associados a períodos de intensa precipitação de vários dias de duração, esses cursos d'água causam erosão severa no sistema de dunas frontais e praia emersa (Figura 6).

Monitoramento de mudanças de volume entre as dunas frontais e a face da praia inferior durante o verão e inverno de 1995 indicaram a retirada de $900 \mathrm{~m}^{3}$ de sedimentos numa área de $420 \mathrm{~m}^{2}$ (Pereira da Silva et al., 2003). Considerando-se a media de ocorrência de 2 sangradouros por quilômetro durante o inverno, primavera e outono, pode-se ter uma idéia do volume de sedimentos erodidos ao longo dos $220 \mathrm{Km}$ de praias entre Rio Grande e Chuí. Nesta extensão as áreas mais suscetíveis a erosão estão representadas pelas regiões compreendidas entre Cassino - Farolete da Verga e Hermenegildo - Chuí. Na primeira, a concentração de sangradouros esta relacionada ao banhado do Taim, cuja influência estende-se até a praia. Na região extremo sul, a concentração deve-se à baixa elevação dos terrenos, associada à presença de banhados localizados no extremo sul da Lagoa Mirim e de extensos depósitos de turfa, os quais reduzem a infiltração aumentando assim descarga pluvial ( Calliari e Pereira da Silva, 1998).

No litoral norte e central, monitoramentos efetuados entre 1991 e 2001 permitiram identificar áreas mais suscetíveis a erosão relacionada à presença dos sangradouros. Altas concentrações são observadas próximo ao Mar Grosso (S.J. do Norte) e Farol de Mostardas (Figueiredo \& Calliari, 2004) em função dos processos de urbanização, geologia sub-superficial e topografia. Devido à existência das Lagoas do Peixe e Estreito as quais recebem a drenagem das áreas mais altas, o numero de sangradouros decresce ao longo dessas áreas. Mais ao norte, entre Mostardas e Tramandaí a presença de várias lagoas costeiras menores distantes 2,5 a $3 \mathrm{Km}$ da praia e que extravasam durante períodos de intensa pluviosidade resulta no aumento do número de sangradouros, cujas dimensões podem ultrapassar $300 \mathrm{~m}$ de largura com $0,5 \mathrm{~m}$ de profundidade. Na porção norte urbanizada da barreira entre Cidreira (ao sul de Tramandaí) e Torres (Figura 1) processos de urbanização associados à redução da área de infiltração e compactação do solo, ambos relacionados a edificações e pavimentação de ruas, visivelmente aumentam a concentração desses cursos d'água. Na maioria dos balneários ao longo da costa do RS, esse fato leva a enchentes relâmpago nas áreas mais baixas, desencadeando sérias conseqüências no saneamento básico e na qualidade da água na zona de arrebentação, uma vez que praticamente inexistem tratamentos de efluentes domésticos nesses locais.
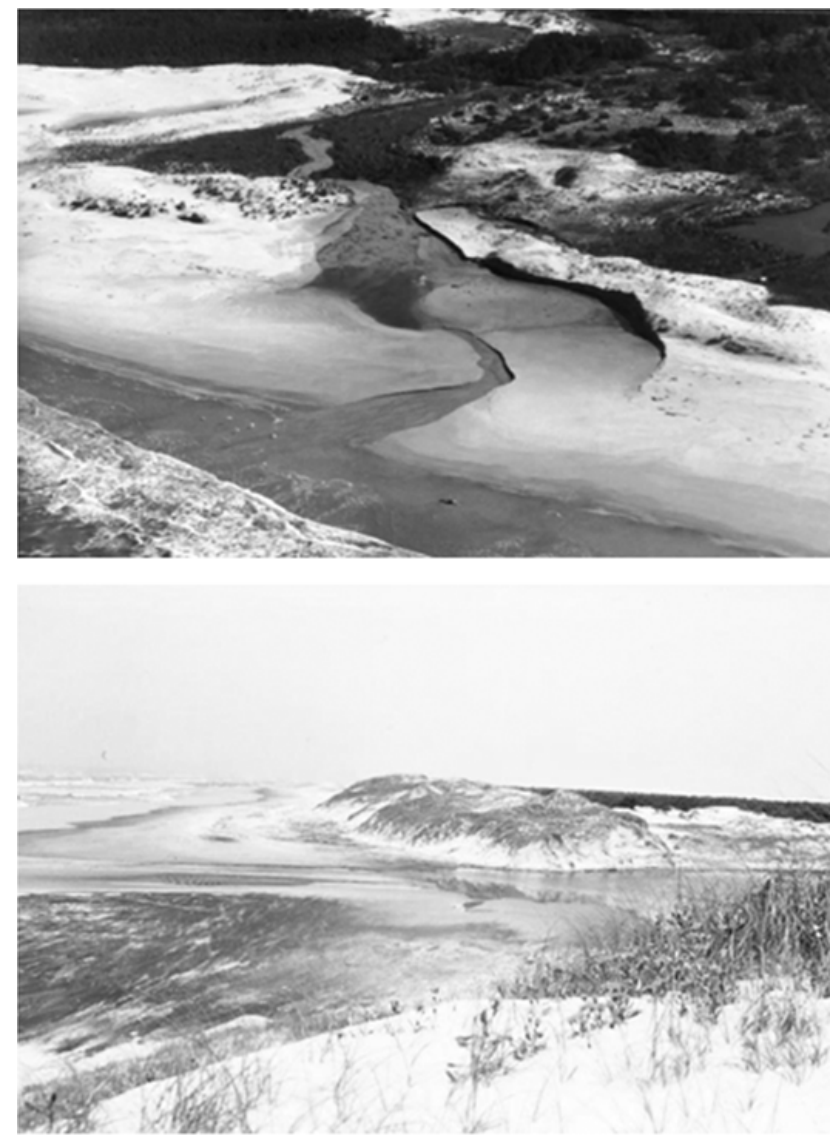

Figura 6. Fotos de sangradouros na costa do RS ressaltando a erosão no sistema de dunas frontais. Fotos: Lauro Calliari.

Sangradouros são também fontes de acidentes graves e fatais. $O$ fato de a areia fina predominar ao longo do litoral propicia boas condições de tráfego de automóveis nas praias. Entretanto, depressões acentuadas comumente são formadas pela escavação destes cursos no pós-praia e na berma, sobretudo após precipitações severas, quando seu fluxo d'água costuma ser sensivelmente amplificado. Estas depressões são de difícil identificação pelos motoristas, sobretudos aqueles usuários ocasionais do litoral, sendo que inúmeros acidentes envolvendo ferimentos graves devido à queda de veículos nestes canais de sangradouros vem sendo documentados, bem como perda de alguns veículos na areia fluidizada com o afloramento do lençol freático.

Quando sangradouros cortam dunas frontais altas, escarpas instáveis com perigo de deslizamento são formadas (Figura 7a). Uma fatalidade foi registrada em novembro de 2001 na localidade de Inhame (proximidades de São José do Norte), quando um garoto de oito anos, o qual se encontrava brincando na margem da escarpa, foi soterrado pelo colapso da duna. Perda de propriedade é também uma séria questão quando construções são colocadas no caminho dos sangradouros (Figura 7b), e principalmente quando a 


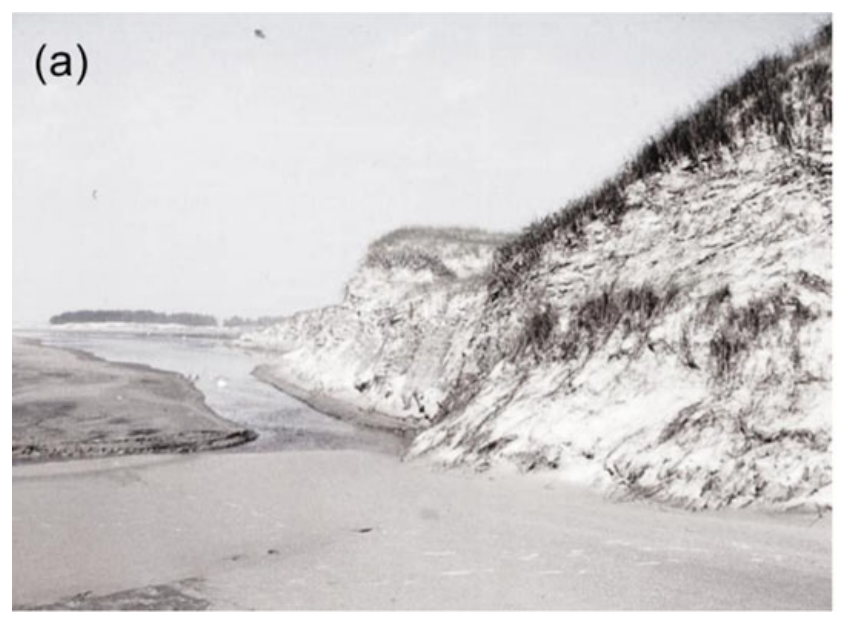

(b)

Figura 7. Escarpas formadas nas dunas frontais (a) e casas construídas próximas ao curso de um sangradouro (b) no litoral do RS. Fotos: Lauro Calliari.

urbanização é feita durante a estação seca, sem um estudo prévio do comportamento sazonal destes cursos d'água efêmeros.

\section{Riscos ao banho de mar associados à morfodinâmica de praias.}

O propósito desta seção é discutir a relação entre os diferentes estágios praiais encontrados no estado do Rio Grande do Sul em relação a riscos eminentes aos banhistas dentro da zona de surfe. As praias selecionadas são as que durante o verão apresentam uma elevada concentração de banhistas próximas a centros urbanos.

A presença de promontórios rochosos junto à zona de arrebentação caracteriza um perigo permanente em algumas praias de Torres, no extremo norte do litoral do RS. O perigo se agrava devido à turbidez característica das águas no local, o que impede muitas vezes que as rochas submersas sejam identificadas pelos banhistas. A presença do promontório norte da praia da Guarita (Figura 8) associada com as fortes correntes encontradas no local a torna um dos locais com maior risco há acidentes de banho da costa do $\mathrm{RS}$.

As praias apresentam perigos distintos aos banhistas de acordo com a morfologia dos sistemas banco-cava, os quais caracterizam os estágios praiais definidos na literatura, como os do modelo de Wright \& Short (1984). Nos estágios do tipo Banco e Cava Longitudinal (BCL), por exemplo, os maiores perigos estão na presença de cavas bem desenvolvidas, as quais comumente podem atingir profundidades superiores à altura dos banhistas. Cavas bastante profundas e próximas à praia têm sido registradas em algumas praias do RS como a Praia Grande em Torres (Pivel, 1997), Tramandaí, Cassino (Pereira \& Calliari, 2005, Pereira, 2005; Guedes, 2006), Hermenegildo (Tozzi, 1999) e Chuí (Calliari \& Klein, 1993).
Estágios de Banco e Praia Rítmicos (BPR) do modelo de Wright \& Short (1984) também são comuns em diversas praias da nossa costa. Os perigos associados a estágios deste tipo se referem à tridimensionalidade dos bancos, o que torna a morfologia da zona de arrebentação complexa, com alta variação de profundidades conforme o banhista se desloca longitudinalmente à praia dentro da zona de arrebentação. Um perigo adicional a estágios deste tipo ocorre com a formação de correntes de retorno, as quais têm sido documentadas em diversas praias do RS, como Capão e Tramandaí (Figura 9). Correntes de retorno comumente formam-se também associadas a estruturas fixas como molhes, como é o caso dos molhes do Rio Mampituba, em Torres (Figura 9a).

A mobilidade das praias caracteriza sua susceptibilidade à troca de sedimentos entre a parte emersa $e$ submersa, e indica a tendência da praia em alternar-se entre diferentes estágios praiais ao longo do tempo. $\mathrm{Na}$ costa do Rio Grande do Sul, esta mobilidade está bas-

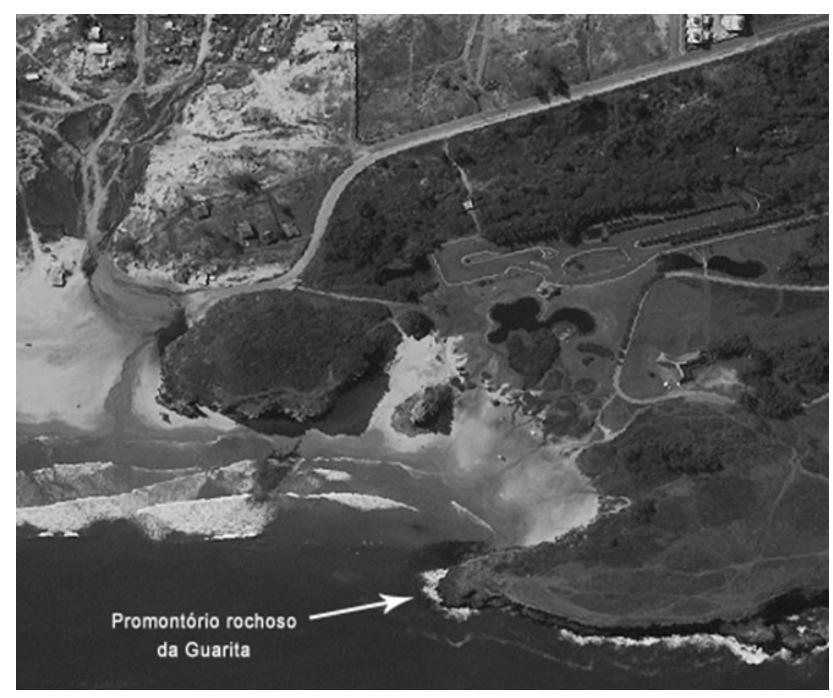

Figura 8. Foto aérea (Sistema ADAR 1000 - LOG/DGEO/FURG) destacando o promontório rochoso da Praia da Guarita, Torres. 
Calliari et al.: Riscos naturais na costa do RS.
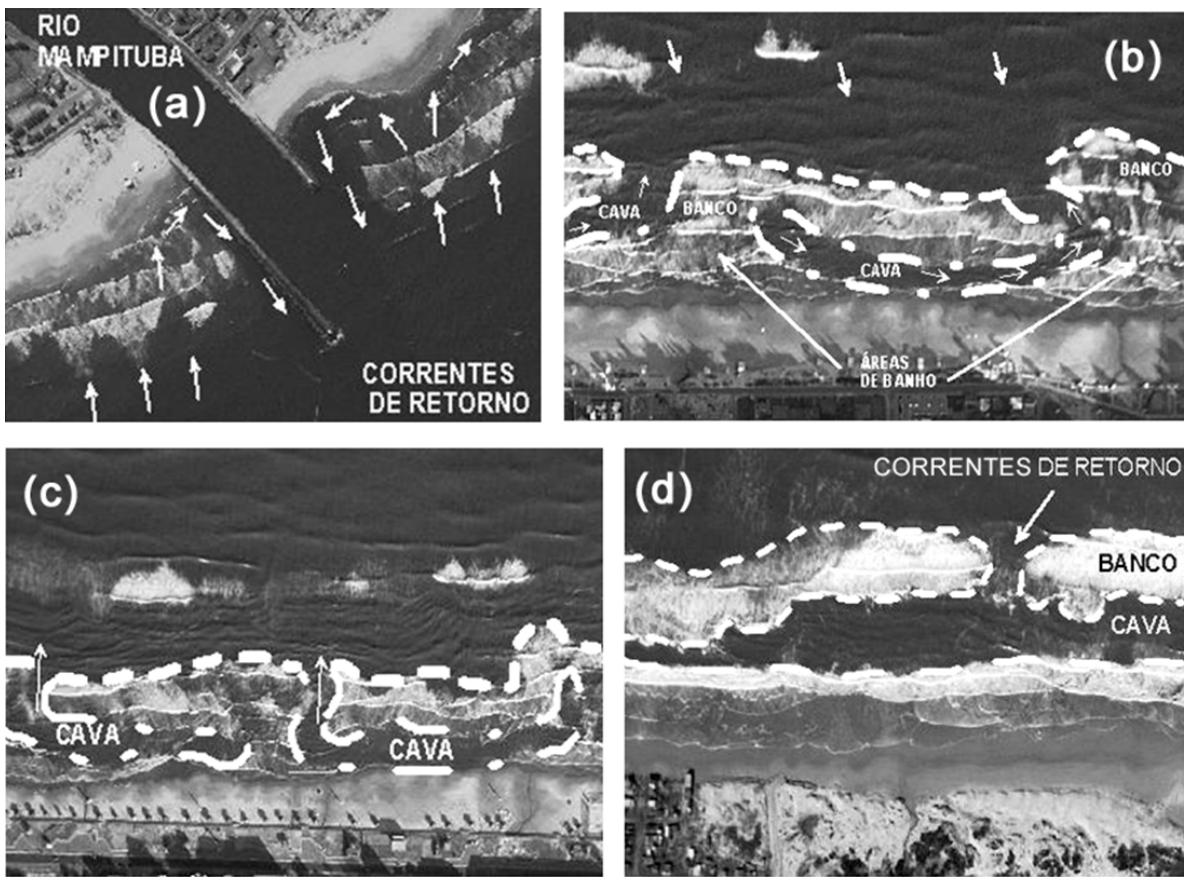

Figura 9. Fotos aéreas (Sistema ADAR 1000 - LOG/DGEO/FURG), destacando: correntes de retorno associadas aos molhes do Rio Mampituba em Torres (a) e sistemas tridimensionais com bancos, cavas e correntes de retorno em Capão (a), Tramandaí (b) e Hermenegildo (c).

tante associada com a granulometria do sedimento que compõe as praias, uma vez que aquelas com maiores porcentagens de areia média, como Praia Grande, Tramandaí, Capão e Hermenegildo, apresentam alta mobilidade, enquanto as praias com baixas porcentagens de areia média se caracterizam por uma mobilidade mais baixa, como o Cassino e o Chuí. No caso do Hermenegildo, a alta mobilidade está associada à presença de altas concentrações de cascalho biodetrítico, encontrados em altas concentrações na face da praia deste local.

A Figura 10 mostra envelopes de perfis realizados ao longo das ultimas últimas duas décadas em algumas das praias mais habitadas do litoral do RS. É possível notar como a Praia Grande, Tramandaí, Capão e Hermenegildo apresentam alta mobilidade, a qual pode ser observada pela grande diferença vertical entre os perfis na parte subaérea da praia, bem como pelos parâmetros morfométricos mostrados na Tabela 1. Esta mobilidade reflete no comportamento intermediário encontrado nos locais, com predominância entre estágios do tipo BCL e BPR, o que caracteriza estes locais como alguns dos mais perigosos da costa do RS.

Cassino e Chuí, por sua vez, caracterizam-se por uma mobilidade consideravelmente mais baixa (Figura 10; Tabela 1), e uma predominância entre estágios dissipativos, com presença de intermediários predominantemente do tipo BCL. As imagens Argus obtidas a partir de 2005 no Cassino de forma simultânea a perfis de alta freqüência, entretanto, têm mostrado que outros estágios também ocorrem nesta praia, a des-

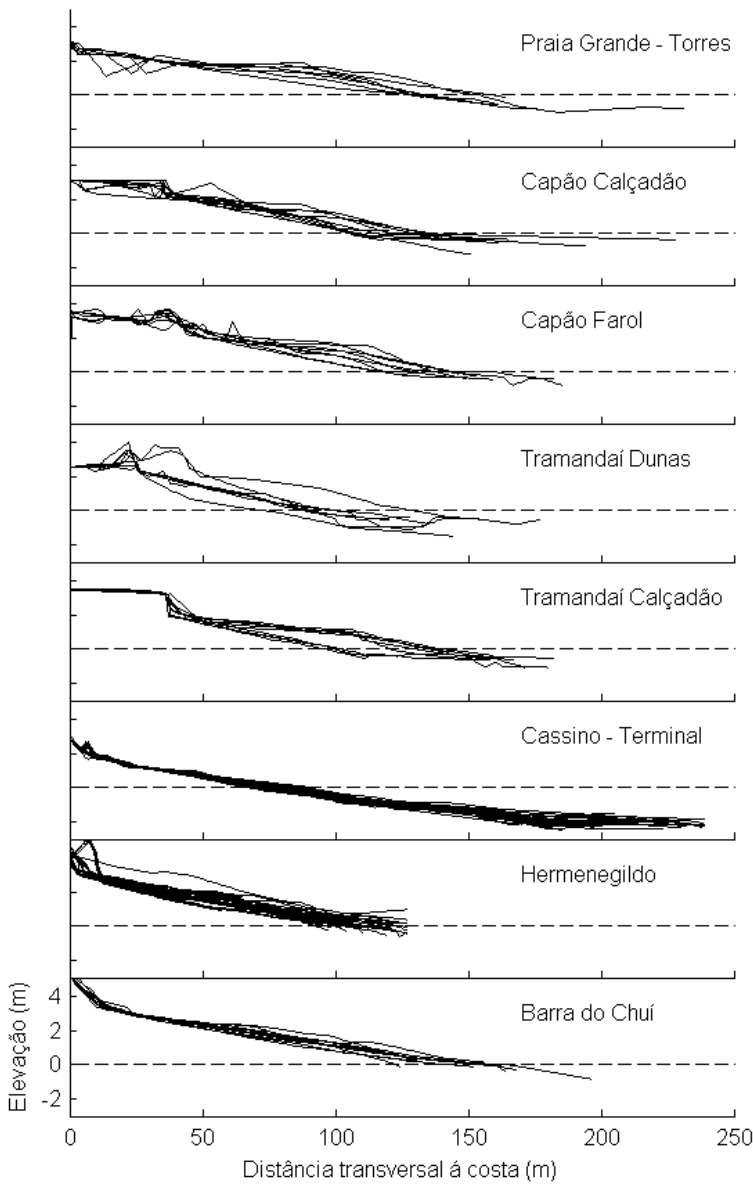

Figura 10. Envelope dos perfis de praias do litoral do RS. 
Tabela 1. Parâmetros morfométricos obtidos em praias do RS. $\mathrm{N}=$ número de levantamentos, yb= largura média da praia, óyb= índice de mobilidade, $C V=$ coeficiente de variação; valores obtidos de: *Pivel (1997); ${ }^{* *}$ Pereira (2005); ***Tozzi (1999).

\begin{tabular}{lcrrr}
\hline \hline Praia & $\boldsymbol{N}$ & $\boldsymbol{y b}$ & $\boldsymbol{\sigma y \boldsymbol { b }}$ & $\boldsymbol{C V}(\%)$ \\
\hline Praia Grande & 8 & 133,7 & 19,2 & 15,0 \\
Capão da Canoa - Calçadão & 9 & 120,6 & 12,1 & 10,3 \\
Capão da Canoa - Farol & 9 & 138,1 & 12,8 & 9,2 \\
Tramandaí - Dunas & 9 & 95,6 & 17,3 & 18,1 \\
Tramandaí - Calçadão & 10 & 117,4 & 17,2 & 14,7 \\
Cassino - Terminal & 52 & 77,0 & 6,2 & 8,1 \\
Hermenegildo & & 85,0 & 20,0 & 23,5 \\
Barra do Chuí & 6 & 48,3 & 3,7 & 1,3 \\
\hline \hline
\end{tabular}

peito de suas características predominantemente dissipativas e de sua granulometria com alta porcentagem de areia muito fina. A Figura 11 mostra mosaicos de imagens Argus de longa exposição obtidos em 2005 no Cassino. Um sistema dissipativo, com três bancos estendendo mar afora até uma distância aproximada de $300 \mathrm{~m}$ da linha de praia pode ser observada na Figura 11a, ao passo que a Figura $11 \mathrm{~b}$ ressalta uma condição de baixa dinâmica, praticamente sem quebra de ondas sobre os bancos. Um estágio BCL é claramente observado na Figura 11c, enquanto um BPR caracteriza a Figura 11d, e bancos com padrões mais caóticos podem ser observados na Figura 11e. Correntes de re-

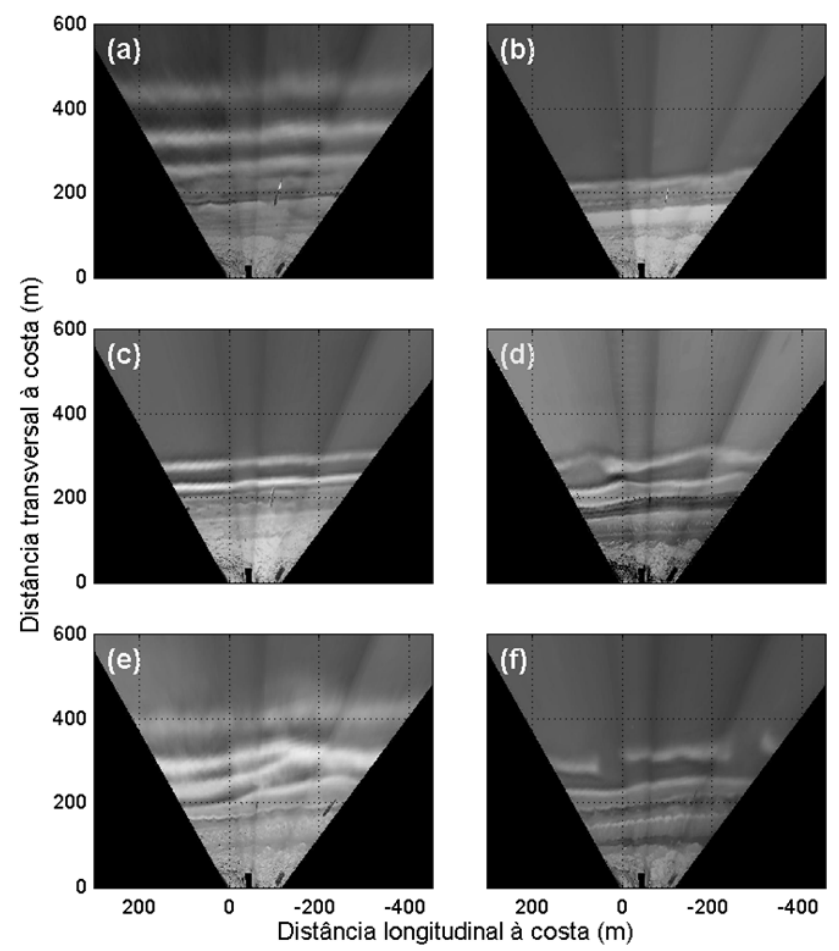

Figura 11. Imagens de longa exposição geradas pelo Sistema Argus Cassino em 2005. As imagens evidenciam um sistema dissipativo (a), com baixa dinâmica (b), BCL (c) BPR (d), bancos irregulares (e) e com correntes de retorno (f). torno, feições características de estágios intermediários têm sido também ocasionalmente identificadas através das vídeo-imagens, como pode ser observado na Figura 11f. Os diagramas tridimensionais da zona de arrebentação do Cassino da Figura 12 (Guedes, 2006) ressaltam dois dos estágios observados na Figura 11, BCL (12a) e BPR (12b).

\section{Riscos associados à deposição de lama fluída na praia e zona de arrebentação.}

Eventos de deposição de lama na zona de arrebentação e praia do Cassino têm ocorrido desde 1901 (Calliari \& Griep, 1999). O processo está associado ao transporte e deposição da lama fluída por ondas de tempestade, e em ao menos duas ocasiões, a presença de lama fluída representou um risco potencial para surfistas. Devido a gradientes laterais resultantes das variações de empilhamento de água junto a costa devido a quebra da onda em função da atenuação das ondas em regiões de lama fluída, correntes litorâneas transportam surfistas para áreas onde a zona de surfe permanece isolada da praia por extensos depósitos de lama fluída, cuja espessura ultrapassa 1,5 m (Calliari et al., 2001). Tal situação causa o aprisionamento dos mesmos na zona de surfe, submetendo-os a risco de vida em função da hipotermia resultante da longa exposição a águas com baixas temperaturas, típicas da região durante as estações de outono e de inverno. Existe também o risco dos mesmos serem imobilizados ou mesmo cobertos pelos depósitos de lama fluída, que em cavas pronunciadas podem atingir maiores espessuras. Felizmente, nas duas situações que se tem registro, pescadores locais e surfistas usando cabos e pranchas do tipo "body-boards" para cruzar o depósito de lama os resgataram (Figura 13).

A presença de lama entre a face da praia e o pós-praia representa um risco adicional, considerandose o alto número de veículos que trafegam sobre a praia do Cassino. Qualquer depósito de lama é rapidamente coberto por uma fina camada de areia assim que o nível do mar baixa após as tempestades. Tal situação torna-se uma armadilha para carros que trafegam em velocidade moderada e são repentinamente parados no bolsão de lama que facilmente atinge $0.3 \mathrm{~m}$ de espessura. Dezenas de acidentes sobre a praia, alguns dos quais envolvendo ferimentos sérios, ocorreram após um evento de deposição de lama em 1998, cujos efeitos permaneceram por mais de um ano.

\section{Riscos associados à movimentação de areia pelo vento.}

Embora como fator de risco de vida e perda de propriedade o transporte de areia pelo vento seja mínimo quando comparado a furacões, enchentes e outros riscos naturais, em alguns locais o transporte de areia 

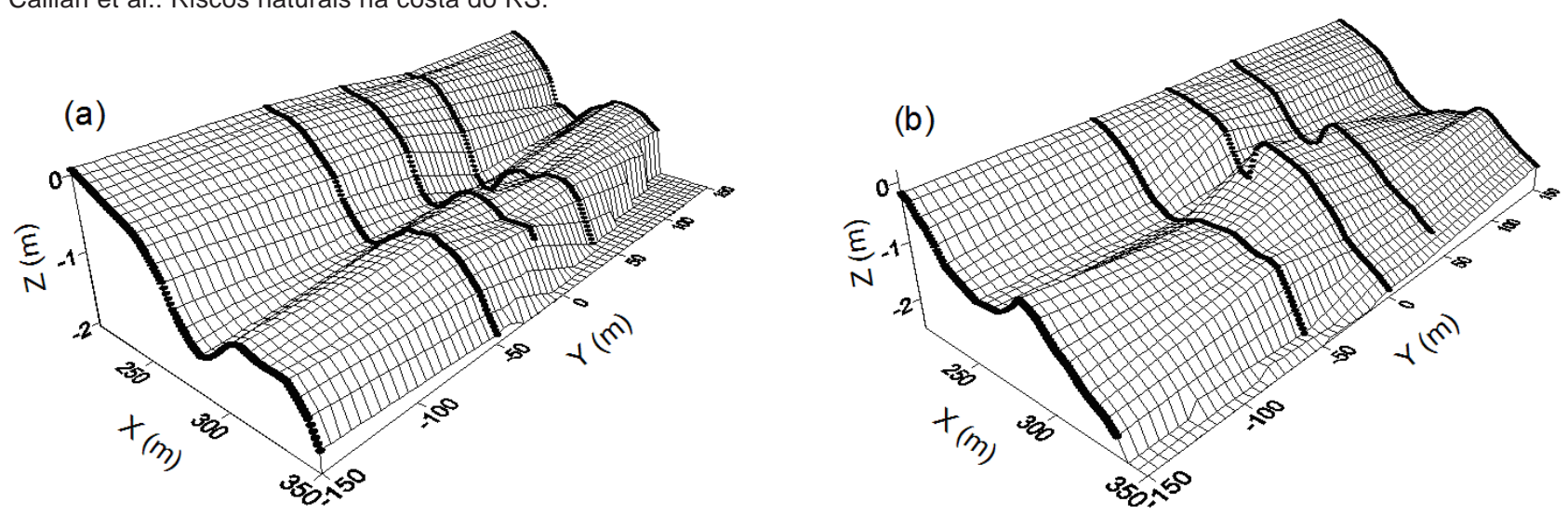

Figura 12. Diagramas tridimensionais da zona de arrebentação no Cassino, obtidos a partir da interpolação de cinco perfis (linhas pretas), ressaltando estagios BCL (a) e BPR (b). Modificado de Guedes (2006).

ameaça vidas e danifica propriedades (Sherman \& Nordostrom, 1994).

A associação entre a orientação da linha de costa e a freqüência e intensidade do vento NE, ao mesmo tempo em que favorece o desenvolvimento de dunas mais altas no setor do litoral norte e central, entre Imbé e Mostardas, também favorece o avanço de grandes lençóis de areia. Estes lençóis se comportam como dunas transgressivas, as quais apresentam riscos uma vez que solapam vários ambientes da planície costeira e mesmo setores urbanizados. Segundo Tomazelli (1992) a freqüência anual do vento NE em Imbé é a maior que em outros setores da costa atingindo $41,4 \%$, sendo máxima na primavera e verão atingindo 53,2\% em dezembro. Cálculos do potencial de deriva de areia pelo vento, realizados pelo mesmo autor, indicaram que o regime de ventos da costa do RS pode ser caracterizado como de alta energia, com o percentual de ventos com capacidade para transporte de areia decrescendo de Imbé $(25,1 \%)$ para Torres $(12,7 \%)$ e daí para Rio Grande (7\%), cálculos esses efetuados com base na intensidade mínima de $5 \mathrm{~m} / \mathrm{s}$ para transporte da areia local pelo vento.

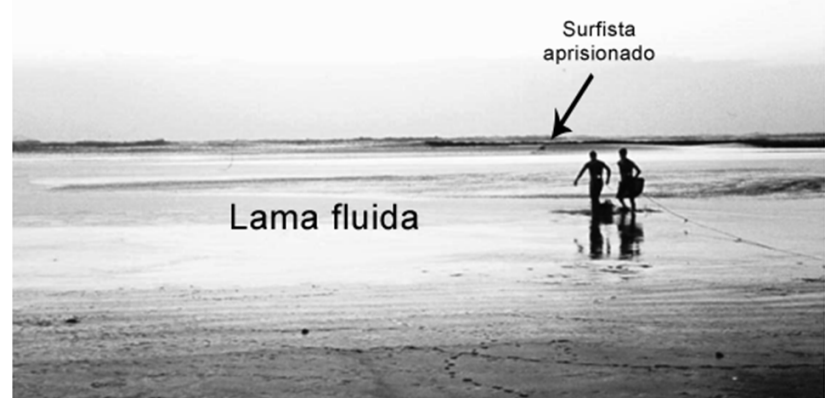

Figura 13. Resgate de um surfista aprisionado no depósito de lama fluida na zona de arrebentação do Cassino. Foto: Lauro Calliari.
No litoral médio, de Mostardas até as proximidades de São José do Norte, onde o vento NE é paralelo à costa ou obliquo com componente em direção ao mar, dunas frontais são reduzidas ou inexistentes, e a progressão de lençóis de areia é mínima. A importância da orientação da linha de costa é reforçada pelo aumento gradativo das dunas nas proximidades de São José do Norte onde o vento novamente apresenta componente em direção à costa, aumentando a altura das dunas para valores entre 2 e 2,5 m. Excepcionalmente pelo efeito de retenção da areia, dunas junto à raiz do molhe leste atingem mais de $10 \mathrm{~m}$. Neste local, perda de propriedade publica estadual representada por escolas e habitações do serviço portuário local foram registradas nas proximidades do molhe leste (Figura 14).

No litoral sul, o aprofundamento artificial dos sangradouros naturais com a finalidade de expandir a plantação de Pinus elliottis para locais alagados (Seeliger et al., 2000), além de induzir rompimento do cordão de dunas frontais, rebaixa o lençol freático, causando a morte da vegetação pioneira das dunas frontais, provocando sua instabilidade e culminando com sua obliteração. A ausência do processo de acresção sazonal de areia pela retenção da vegetação rompe o processo de retroalimentação da praia durante marés meteorológicas e facilita o transporte de areia em direção ao continente pelos ventos dominantes. Taxas de migração segundo o autor excedem a $30 \mathrm{~m} / \mathrm{ano}$ e formam grandes lençóis de areia sobre pântanos e dunas de retenção contra a margem de antigas plantações de Pinus.

Além da erosão das dunas frontais e da redução de ambientes úmidos, perda de propriedade e acidentes fatais são registrados pela migração de areia. A movimentação das dunas frontais na praia de Tramandaí após episódios contínuos de vento NE fortes resultou no solapamento e desmoronamento da parede de uma casa, causando a morte de adultos e crianças que dor- 
miam numa noite do verão de 2003. Vários outros setores costeiros com urbanização sobre dunas interiorizadas (a exemplo de São José do Norte) estão sob o mesmo processo.

\section{CONCLUSÕES}

Processos relacionados à hidrodinâmica, geomorfologia e movimentação de sedimentos representam perigos costeiros no litoral do estado do Rio Grande do Sul (RS), os quais se tornam riscos quando da presença de áreas urbanizadas. Os riscos implicam em erosão costeira, mudanças ambientais e acidentes graves incluindo fatalidades a usuários da zona costeira. Padrões de refração de ondas associados à incidência de ondas de Sudeste Sul e Sudoeste causam erosão em dois setores da costa, um no litoral Norte nas proximidades do farol da Conceição e outro no extremo sul entre as praias de Hermenegildo e Chuí. Em ambas as regiões, a elevada concentração de sangradouros amplifica a erosão pela destruição das dunas frontais e praia emersa. Adicionalmente os setores emersos mais baixos da barreira adjacentes a pequenas lagoas são mais suscetíveis a erosão por sangradouros. Tanto os padrões de refração como os sangradouros estão associados a dois padrões de trajetórias de tempestade e ciclones extratropicais que propiciam maior erosão e inundação da zona costeira.

A associação entre praias com elevado número de banhistas e características morfodinâmicas intermediárias (praia dissipativas com múltiplos bancos) em função da textura dos sedimentos elevam o risco da ocorrência de acidentes de banho no litoral norte e no extremo sul do RS. Mesmo com número de usuários semelhante às praias mais freqüentadas do litoral norte, os $12 \mathrm{Km}$ da Praia do Cassino localizados entre o molhe oeste e as proximidades do naufrágio do Navio Altair, caracterizados por praias dissipativas com a areia mais fina da costa do RS, representam o setor de praia com menor risco a acidentes de banho.

A orientação da costa em relação ao vento predominante de NE proporciona a invasão de areia em direção a planície costeira na forma de dunas transgressivas no setor do litoral norte entre Tramandaí e Mostardas e em São José do Norte.

Eventos esporádicos de deposição de lama durante tempestades na praia do Cassino produzem gradientes pronunciados em processos hidrodinâmicos. Esses gradientes influenciam o comportamento morfodinâmico destes setores e causam riscos costeiros relacionados ao uso da praia. Os dados mostram

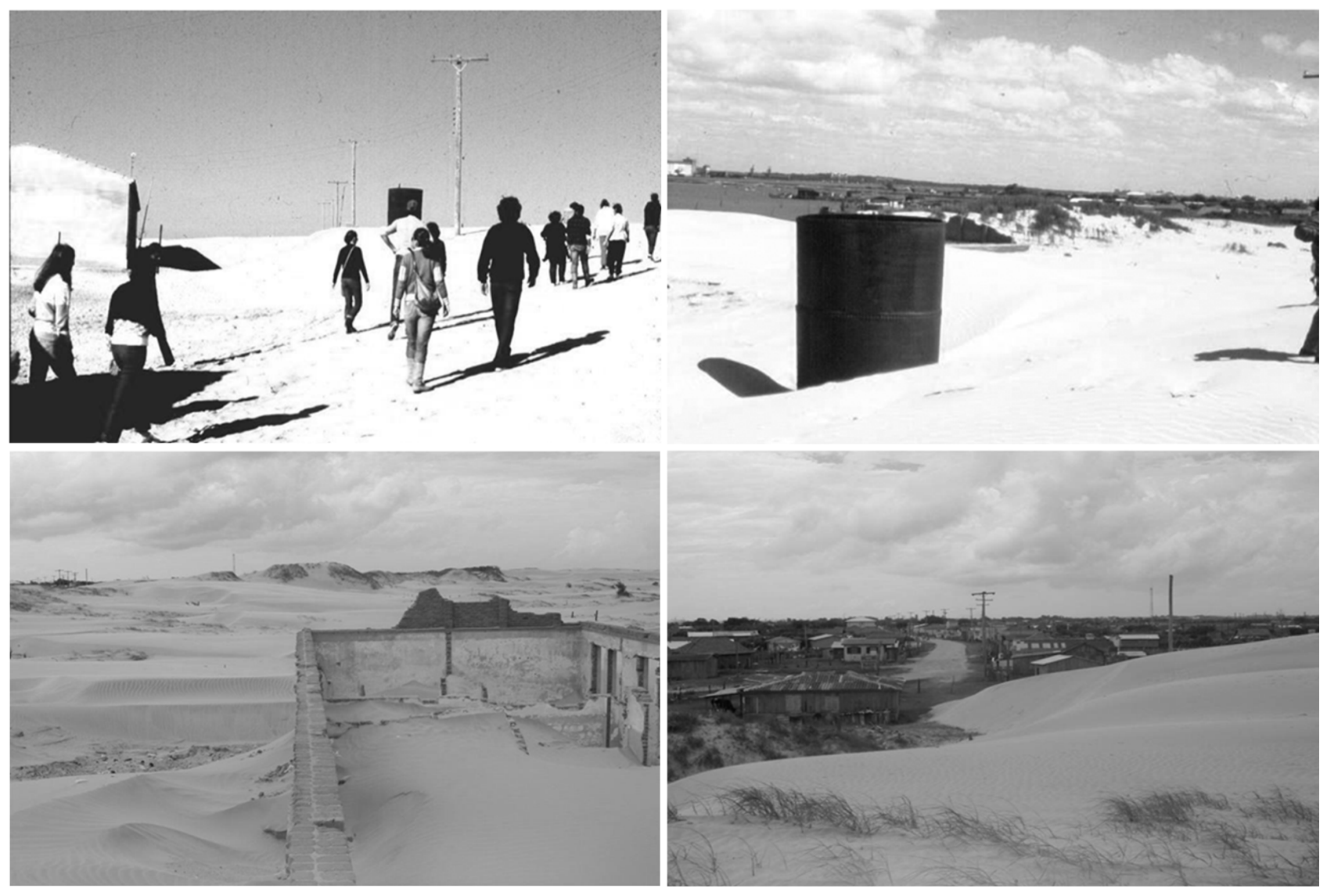

Figura 14. Fotos mostrando o avanço de areia sobre propriedades do município de São José do Norte. Fotos: Lauro Calliari. 
Calliari et al.: Riscos naturais na costa do RS.

que para a erosão, além do mapeamento, esforços devem ser dirigidos ao entendimento dos processos. Os aspectos relacionados aos sangradouros mostram que problemas de urbanização e riscos podem ser evitados se a distribuição e comportamento dos mesmos forem entendidos e incluídos nos planos de ocupação. Esforços especiais devem ser concentrados na confecção de mapas topográficos altamente detalhados da zona costeira. Da mesma forma, riscos associados à movimentação de areia devem ser mitigados com planejamento e fixação de dunas. Perigos associados às praias são basicamente não permanentes, porém potencialmente perigosos. Deposição de lama apesar de esporádica induz riscos potenciais.

\section{REFERÊNCIAS BIBLIOGRÁFICAS}

Araujo, R.S.; Sprovieri, F.C.; Freitas, D.; Klein, A.H.F. Variação da Morfologia Praial e Identificação de Zonas de Erosão Acentuada (ZEA) na Enseada do Itapocorói - SC.2009. Brazilian Journal of Aquatic Science and Technology, volume 12 (2), (no prelo), Itajaí, SC.

Barletta, R.C. \& Calliari, L.J. 2001. Determinação da intensidade das tempestades que atuam no litoral do Rio Grande do Sul, Brasil. Pesquisas. 28 (2): 117-124.

Barletta, R.C. \& Calliari, L.J., 2003. An assessment of the atmospheric and wave aspects determining beach morphodynamic characteristics along the central coast of RS State, Southern Brazil. Journal of Coastal Research. 35 (SI): 303-308.

Buchmann, F.S.C. \& Tomazelli, L.J. 2003. Relict Nearshore Shoals of Rio Grande do Sul, Southern Brazil: Origin and Effects on Nearby Modern Beaches. Journal of Coastal Research. 35 (SI): 318322.

Calliari, L.J. \& Klein, A.H.F. 1993. Características morfodinâmicas e sedimentológicas das praias oceânicas entre Rio Grande e Chuí, R.S. Pesquisas. 20 (1): 48-56.

Calliari, L.J. \& Pereira da Silva, R. 1998. Erosion Processes associated to storm surge and washout along the southern Brazilian coastline. Journal of Coastal Research. 26 (SI): 1-7.

Calliari, L. J.; Tozzi, H.A.M. \& Klein, A. H. F. 1998. Beach Response to Storm Surge in Southern Brazil. Academia Brasileira de Ciências. 70 (2): 231-247.

Calliari, L.J. \& Griep, M.F. 1999. Uma análise histórica dos efeitos produzidos por modificações antrópicas no estuário da Lagoa dos Patos - Natural versus provocado. In: Flores, F.N. (Ed) Por uma história multidisciplinar do Rio Grande, Edigraf FURG Rio Grande.97-105pp.
Calliari, L.J.; Speranski, N.S.; Torronteguy, M. \& Oliveira, M.B. 2001. The mud banks of Cassino beach, Southern Brazil: Characteristics, Process and Effects. Journal of Coastal Research. 34 (SI): 318325.

Calliari, L.J.; Pereira, P.S.; Oliveira, A.O. \& Figueiredo, S.A. 2005. Variabilidade das dunas frontais no litoral norte e médio do Rio Grande do Sul, Brasil. Gravel. 3: 15-30.

Figueiredo, S.A. \& Calliari, L.J. 2004. Washouts in the central and northern littoral of Rio Grande do Sul state, Brazil: distribution and implications. Journal of Coastal Research. 39 (SI): 366-370.

Guedes, R.M.C. 2006. Morfodinâmica de Alta Freqüência de um Sistema Praial com Bancos Triplos Durante o Experimento Cassino 2005. Monografia de Graduação. FURG. 84 p.

Guedes, R.M.C. 2008. Utilização de Métodos Diretos e Vídeo-Imagens Argus na Caracterização Morfodinâmica da Zona de Arrebentação da Praia do Cassino, RS. Dissertação de Mestrado. FURG. $93 \mathrm{p}$.

Klein, A.H.F.; Araujo, R.S.; Polette, M.; Sperb, R.M.; Freitas, D.; Camargo, J.M.; Sprovieri, F.C.; Pinto, F.T. 2009. Ameliorative Strategies at Balneário Piçarras Beach - Brazil. In: Williams, A.T. and Micallef, A. (ed). Beach Management Guidelines: Principles and Practice. Earthscan Publisher, London, UK. 241-255.

Lippmann, T.C. \& Holman, R.A. 1989. Quantification of Sand Bar Morphology: A Video Technique Based on Wave Dissipation. Journal of Geophysical Research. 94 (C1): 995-1011.

Marone, E. \& Camargo, R. 1994. Marés meteorológicas no litoral do Estado do Paraná. O evento de 18 de agosto de 1993. Nerítica. 8: 73-85.

McNinch, J.E. 2004. Geologic control in the nearshore: shore-oblique sandbars and shoreline erosional hotspots, Mid-Atlantic Bight, USA. Marine Geology. 211 (1-2): 121-141.

Parise, C.K. 2007. Padrões atmosféricos sinóticos geradores de marés meteorológicas intensas e a resposta morfodinâmica da praia do Cassino. Monografia de graduação. FURG. 77p.

Pereira da Silva, R.; Calliari, L.J. \& Tozzi, H.A.M. 2003. The Influence of Washouts on the Erosive Susceptibility of Rio Grande do Sul between Cassino and Chuí Beaches, Southern Brazil. Journal of Coastal Research. 35 (SI): 332-338.

Pereira, P.S. 2005. Variabilidade da Orla Oceânica do Rio Grande do Sul e Suas Implicações na Elaboração de Planos de Contingência: Aspectos Morfodinâmicos, Sedimentológicos e Geomorfológicos. Dissertação de Mestrado. FURG. 160p. 
Pereira, P.S. \& Calliari, L.J. 2005. Variação Morfodinâmica Diária da Praia do Cassino, RS, Durante os Verões de 2002/2003 no Setor do Terminal Turístico. Braz. J. Aquat. Sci. Technol. 9 (1): 7-11.

Pimenta, F.M. 1999. Caracterização dos regimes de refração de onda ao longo da zona costeira do Rio Grande do Sul. Monografia de Graduação. FURG. $66 p$.

Pivel, M.A.G. 1997. Caracterização morfodinâmica e sedimentológica das praias de Torres (RS). Monografia de graduação. FURG. 72 p.

Saraiva, J.M.B.; Bedran, C. \& Carneiro, C. 2003. Monitoring of Storm Surges on Cassino Beach. Jounal of Coastal Research. 35 (SI): 323-331.

Seeliger, U.; Cordazzo, C.V.; Oliveira, C.P.L. \& Seeliger, M. 2000. Long-Term changes of coastal foredunes in the southwest Atlantic. Journal of Coastal Research. 16 (4): 1068-1073.

Sherman, D.J. \& Nordostrom, K.F. 1994. Hazards of Wind-Blown sand and coastal sand drifts: A Review. Journal of Coastal Research. 12 (SI): 263-275.

Short, A.D \& Hesp, P.A. 1982. Wave, beach and Dune Interactions in Southeastern Australia. Marine Geology. 48: 259-284.

Siegle, E. 1997. Distribuição de sedimentos litorâneos entre o Farol da Conceição e Farol do Chuí, R.S., e fatores condicionantes. Monografia de Graduação. FURG. 91p.

Speranski, N. \& Calliari, L.J. 2001. Bathymetric Lenses and Localized Coastal Erosion in Southern Brazil. Journal of Coastal Research. 34: 209-215.

Speranski, N.S. \& Calliari, L.J., 2006. Padrões de refração de ondas para a costa do Rio Grande do Sul e sua relação com a erosão costeira. In: Muehe, D. (ed) Erosão e progradação do litoral brasileiro. MMA Brasília. 446-454pp.

Tomazelli, L.J. 1992. O regime dos ventos e a taxa de migração das dunas eólicas costeiras do Rio Grande do Sul, Brasil. Pesquisas. 20 (1): 18-26.

Tozzi, H.A.M. 1999. Influência das tempestades extratropicais sobre o estoque subaéreo das praias entre Rio Grande e Chuí, RS. Campanha do Outono e Inverno de 1996. Dissertação de mestrado. UFRGS. $115 \mathrm{p}$.

Wright, L.D. \& Short, A.D. 1984. Morphodynamics variability of surf zones and beaches: A synthesis. Marine Geology. 56: 93-118. 